\title{
The Short- and Long-Term Effects of Development Projects: Evidence from Ethiopia
}

\author{
Ivica Petrikova, UCL \\ Forthcoming in Journal of International Development
}

\begin{abstract}
This paper examines the short-term and long-term impact of development projects on recipients' wellbeing in Ethiopia. Specifically, it compares the effects of five types of development projects unconditional and conditional direct transfers, agricultural and social-infrastructure knowledge transfers, and credit projects - on children's nutrition and on household consumption and income levels. The main finding is that knowledge transfers have the largest positive impact on children's nutritional status and household consumption, in both the short and the long term. The impact of direct transfers on children's health is also positive but less significant whereas the effect of credit projects is here undetectable.
\end{abstract}

Keywords: development projects, short and long-term effects, impact heterogeneity, Ethiopia

\section{Acknowledgement}

The data used in this paper comes from Young Lives, a 15-year study of the changing nature of childhood poverty in Ethiopia, India (Andhra Pradesh), Peru, and Vietnam (www.younglives.org.uk). Young Lives is core-funded by UK aid from the Department for International Development (DFID) and co-funded from 2010 to 2014 by the Netherlands Ministry of Foreign Affairs. The views expressed here are those of the author. They are not necessarily those of Young Lives, the University of Oxford, DFID or other funders.

\section{Introduction}

Sustainable development is often defined and discussed in merely environmental terms, as the effort to ensure that the opportunities and means available to the present generations are going to be available in equal measure to future generations as well. Anand and Sen (2000) have argued against this stance, positing that it is inherently immoral to be concerned about the wellbeing of future generations while ignoring the plight of the present ones. This rebuke is generally not applicable to development workers, as these are usually involved with attempts to improve the condition of the less fortunate in one way or another. At the same time, however, development practitioners rarely expand the definition of sustainability to denote the permanence, or lack thereof, of the improvements that their projects aim to bring about. The main objective of this study is to help remedy this omission by examining how lasting such improvements indeed are. 
In 2011, the latest year for which data are currently available, donors across the world spent more than 180 billion US dollars on development aid (DAC, 2013). Accounting for the fact that some money is disbursed to countries directly as budget support and assuming that an average development project's budget is one hundred thousand dollars, the sum suggests that approximately one and a half million development projects are being implemented globally as we speak. At the same time, progress on the development front recently has been quite meagre. For example, FAO's annual State of Food Insecurity in the World found that in 2012, 870 million people still suffered from undernourishment. Although major improvements in the field were achieved in the 1990s, the rate of progress in combating hunger has slowed down significantly since 2007-2008 (FAO, 2012). A myriad of factors could, of course, be blamed for this deceleration, with a prime place going to the global recession of 2008. Nevertheless, if the effects of development projects were truly positive and sustainable, steadier development achievements would undoubtedly follow.

In this paper, I focus on Ethiopia, a country that is no stranger either to development problems, with 41 per cent of the population undernourished and 30 per cent living in poverty, or to development aid, having received 3.5 billion US dollars in 2011 only, which would according to my calculations indicate the presence of 30 thousand ongoing development projects (WDI, 2013; DAC, 2013). Using data from the Young Lives initiative, I examine the impact of five broad types of development projects - unconditional and conditional direct transfers, agricultural and socialinfrastructural knowledge transfers, and credit projects - on recipients' wellbeing, during their implementation phase and after the cessation of disbursements. The results attained add to the existing pool of knowledge on the effects of different types of development projects on recipients' short-term welfare. More importantly, they contribute to the literature on development sustainability, by demonstrating whether small-scale development initiatives manage to exert a lasting change on poor people's quality of life.

This document proceeds as follows. The next section discusses the theory behind the choice of the dependent variables used, divides development projects into different types based on their 
approach to sustainability, presents the existing literature on their impact and its (non)lasting nature, contextualises the issues to Ethiopia, and formulates hypotheses. The third part describes the data used and introduces some basic descriptive statistics. Section four talks about the empirical methods utilised and explains the reasons underlying their choice. Finally, parts five, six, and seven display the results obtained, discuss them, and offer some concluding remarks.

\section{Literature Review}

\section{Choice of Outcome Indicators}

Most literature examining the impact of development projects on recipients' wellbeing focuses on household income or consumption but in this paper I have somewhat uniquely chosen children's nutritional status as my primary dependent variable. Proper child nutrition is a highly desirable outcome in its own right, as malnutrition in young age can inflict significant damage on children's IQ levels and cognitive functioning (Grantham-McGregor, 1995). Results suggest that nutritional status is also one of the key determinants of children's school-enrolment and completion rates, and hence in turn of their earning potential (Alderman et al., 2001).

In addition, using nutritional-status variables to approximate household consumption levels ${ }^{1}$ has certain benefits. First, children's weight and height assessed by official data collectors are believed to be more reliable measures than self-reported income or consumption and second, they constitute a more cumulative outcome variable (Carter and Maluccio, 2003; WHO, 2006). Another virtue of nutritional-status indicators is that there is no systematic measurement error correlated with the respondents' characteristics, as a result of which any bias in estimated effects tends towards zero (Strauss and Thomas, 1998).

However, not all small-scale development projects aim to improve recipients' nutritional status and even though they might eventually have some effect on the indicator, their link might be too indirect to be become evident in a timeframe of less than one decade. Therefore, as secondary dependent variables, I use self-reported household income and consumption levels. Corresponding 
results between the primary and secondary dependent variables then suggest that a rise in income and consumption has translated into better nutritional status among recipients' children. On the other hand, differing outcomes would indicate that an increase in income has been saved rather than consumed or that increased consumption took place primarily in the non-food department.

\section{Project Categorization by Sustainability}

An oft-quoted Chinese saying, dating to Mao Tse Tung, posits that if you give a man a fish, he will be hungry the next day, but if you teach him how to fish, he will have enough food the whole year (de Graaf, 1986). While multiple problems have been found with the saying - how about teaching a woman how to fish? or what if the man is not interested in fishing at all? - it still provides a useful framework for categorizing development projects according to their potential theoretical sustainability (ibid).

Projects that 'give people fish' constitute the direct-transfer category, where donors distribute cash, food or other materials directly to project participants. These distributions can be unconditional, where recipients are selected on some basis and then directly given the transfers, or conditional, where recipients are expected to provide work or fulfil other conditions in exchange for the transfers. From a long-term perspective, unconditional direct-transfer projects are the least sustainable since once the transfers stop little is left behind by the project. Conditional transfers might be somewhat more sustainable since if recipients worked to qualify for the transfers, they might have acquired some useful skills. Nevertheless, even unconditional transfers might have some positive long-term effects, particularly if they helped people with consumption-smoothing at a time of crisis, hence preventing the selling of assets or some other destructive behaviour.

Projects that 'teach people how to fish' can be labelled as knowledge-transfer projects. With a view to children's nutritional status constituting the main dependent variable in this study, these can be further divided into knowledge-transfer projects with an agricultural focus (e.g. extension projects) versus those with a social-infrastructure focus (e.g. health and education training, nutrition 
and hygiene counselling). Theoretically, these projects should have more lasting impacts than directtransfer ones as the skills and knowledge that they teach stay behind even after the projects finish. Furthermore, through spill-over effects, the newly learned practices might be adopted by participants' neighbours, friends, and family (Kremer, 2003). However, long-term sustainability can still be questioned especially if the new practices require expensive external inputs originally paid for by the project funding. Furthermore, there is no guarantee that the knowledge transferred to one generation will be passed on further down.

A variation on the previous category are projects that 'give a man a loan so that he can buy a fishing rod,' aka credit/microfinance projects. In theory, these projects are highly economically sustainable, as participants' increasing profits and repaid loans with interest should enable the lending institutions, originally capitalised with donor money, to sustain themselves indefinitely. The social sustainability side of the projects, however, is more questionable as loans might be provided only to the more affluent members of the project community, in which case the impact of the projects on the very poor could be non-existent both in the short and in the long run.

Finally, some development programmes working at the macro level attempt to intervene in the functioning of the partner country in order to 'turn the purchase of fishing rods and acquisition of fishing skills into a more efficient process' (Taylor, 2013). However, since this paper works with a household-level dataset that reports only participation in development projects that affected the households surveyed directly, I cannot examine the effects of this last category.

Impact of the Different Types of Development Projects on Recipients' Wellbeing

\section{Direct-Transfer Projects, Unconditional and Conditional}

Most researchers regard the short-term effect of direct transfers on recipients' wellbeing to be positive. Disagreement exists on whether the transfers should contain a conditionality clause, with some authors finding it essential in instilling desired behaviour in recipients (e.g. Baird et al., 2011) while others seeing it as unnecessarily undermining the social protection of development 
programmes (Samson, 2006). Few examinations of the long-term impact of direct-transfer projects exist as most researchers deem them a tool used primarily during emergencies (e.g. Quisumbing, 2003). However, since nutritional status reflects the quantity and quality of consumption over time, it is possible that transfers of food and cash have some lasting positive impacts on children's weight and height even after they have been discontinued. On the other hand, research suggests that continued transfers of food discourage countries' local food production (Gelan, 2007; Tadesse and Shively, 2009).

\section{Agricultural Knowledge-Transfer Projects}

Existing research vis-à-vis the short-term effects of agricultural projects on recipients' nutritional and other wellbeing is plentiful. One conclusion shared by many authors has been that while agricultural interventions generally increase crop production and consumption levels, nutritional outcomes including children's height-for-age and weight-for-age scores are affected only occasionally (Berti et al., 2004; IYCN, 2011). Other researchers have warned that the programmes often fail to reach the poorest, most marginalised farmers (Fiallos and Cantero, 2008). Berti et al. (2004) reviewed nine studies that evaluated also the long-term effects of agricultural projects and half of them found some lasting positive impact on recipients' financial or human capital even if not always on their nutritional outcomes.

\section{$\underline{\text { Social-Infrastructure Knowledge-Transfer Projects }}$}

The impact of social-infrastructure (education, health, water and sanitation...) knowledgetransfer projects has also been examined frequently, but particularly with regard to recipients' income and consumption. One of the few empirical studies to link these projects with nutritional outcomes specifically, Bhutta et al. (2008) looked at the short-term impact of nutritional counselling on children's health and found that both the promotion of breast feeding and education about complementary infant feeding had a positive impact on children's height-for-age. Hoque et al. 
(1996) assessed the effects of a hygiene-education project in Bangladesh five years after the project has finished and discovered no difference between the treatment and control group in terms of their sanitation knowledge. On the other hand, Chen et al. (2009) analysed the impact of a World-Bank project in China four years after the cessation of disbursements and found knowledge-transfer aspects of the project, on farming and on animal husbandry, to still bear a positive impact on their recipients. Interestingly, the impact on household income appeared much larger in size than on consumption, suggesting that a large portion of the extra funds were saved by families as insurance.

\section{Credit and Finance Projects}

Studies on the short-term impact of credit projects, particularly microfinance ones, have found them to be at least partially successful at reducing recipients' poverty. Copestake et al. (2001) examined a Zambian microfinance institution and found that microloans increased household incomes but only among families that took out a second loan. Imai and Azam (2012) demonstrated on a case study of Bangladesh that microfinance loans taken out for productive purposes augmented household incomes but that this positive impact decreased with time. Looking at the impact of credit projects on nutritional outcomes, Panjaitan and Cloud (1999) found that if provided to women, microcredit improved the wellbeing of families including their nutritional status and in addition reduced women's fertility and increased their participation in family decision-making. In one of the few papers that evaluated the long-term effects of microfinance, Berhane and Gardebroek (2012) found credit projects to have lasting positive impacts particularly on the consumption levels of longtime borrowers.

\section{Contextualization of the Issues to Ethiopia}

Ethiopia is a country highly suitable for the study of the impact of different types of development projects. Even though it has experienced significant poverty reduction in recent years, its GDP per capita is only 410 USD and 30 per cent of its population lives below the national poverty line (WDI, 
2013). There is also a lot left to be desired on the food security and child nutrition fronts. Currently, 44 per cent of children under five in Ethiopia are stunted (too short for age), 35 per cent are underweight (too light for age), and 12 per cent are wasted (too light for height) (WDI, 2013). Stunted children complete on average 1.1 years less in school than healthy children and child mortality associated with undernourishment has depleted the work force by 8 per cent (WFP, 2013).

Development programmes and projects, both national and international, to address Ethiopia's food insecurity and poverty have been around for decades. The largest one currently, a nation-wide Productive Safety Net Programme (PSNP), was put in place in 2005. Its two key instruments - a foodfor-work programme and a direct food/cash distribution programme - have, however, been ongoing for years under different names, offering employment to food insecure people capable of working while providing unconditional transfers of food and money to the disabled, children, and the elderly. Gilligan and Hoddinott (2007) evaluated the PSNP's predecessors, the Employment Generation Scheme (EGS) and the Free Food Distribution (FFD) programme and discovered that although both bolstered recipients' consumption levels, only the EGS decreased perceived famine risk. Gilligan et al. (2009) also evaluated the PSNP and found its impact on recipients' poverty levels to be quite ambiguous, significantly positive only when using certain definitions of the treatment group and of poverty. The impact appeared stronger for families who also received agricultural support.

Another large programme in place is the Community-Based Nutrition (CBN), administered by the World Bank, which aims to improve nutrition and health awareness among mothers and has reached more than one million children so far. A recent evaluation has shown that the programme did improve recipients' knowledge about health and nutrition and reduced children's stunting rates (White and Mason, 2012).

A myriad other development projects are currently being implemented in Ethiopia including many microfinance projects. One of the many was analysed by Schrieder and Sharma (1999), who found that the credit project improved children's height-for-age and weight-for-age scores but had no impact on maternal BMI scores. 


\section{Hypotheses}

On the basis of the theoretical deliberations and existing research summarised above, I expect to find direct-transfer projects, both conditional and unconditional, to have a strongly positive impact on participants' wellbeing outcomes in the short run and a weakly positive or nonexistent impact after the projects' disbursements have ended. With regard to knowledge-transfer projects, I foresee them to have a positive effect on recipients' welfare both in the short and in the long run. Finally, I expect credit projects to have the most long-lasting impact on the consumption levels of participating households and probably also on their children's nutritional status, although perhaps not the strongest one in the short term.

\section{Data and Descriptive Statistics}

This study uses data from the Young Lives project, an international longitudinal analysis of childhood poverty. Information has been gathered on children and their families in four countries India, Vietnam, Ethiopia, and Peru - in three rounds. The first round was carried out in 2002, when the children examined were between 6 and 18 months old; the subsequent rounds took place in 2006 and in $2009^{2}$. This paper focuses on the data collected in Ethiopia on approximately 2000 children from 100 different villages across the country. Moreover, since detailed data on project participation were collected only during the second and third rounds, I analyse only the impact of projects on recipients' wellbeing after $2006^{3}$. My resultant dataset is thus a panel that comprises two time periods only.

\section{Outcome Variables}

Table 1 presents descriptive statistics for the outcome and project treatment variables. As I have mentioned above, my primary variable of interest is children's nutritional status, measured here by the incidence of children that are underweight (too light for their age), stunted (too short for their age), and under-BMI (too low BMI for their age). The rates were calculated by designating all 
children with weight-for-age Z-scores below negative two as underweight, children with height-forage Z-scores below negative two as stunted, and children with BMI-for-age Z-scores below negative two as under-BMI ${ }^{4}$ WHO, 2006). While all three indicators capture some aspect of children's nutritional status, they are not identical. Rates of stunting are particularly relevant when looking at chronic undernourishment, underweight levels when examining the effects of sudden food crises, and under-BMI levels as children approach adulthood (WHO, 2006). As secondary outcomes of interest, I use monthly household consumption levels (self-reported, calculated by Young Lives) and total annual household income levels (self-reported, calculated by author).

The first part of the table shows that the rates of underweight and under-BMI children increased from 23 and 8 per in 2006 to 32 and 20 per cent in 2009, respectively. On the other hand, the rate of stunting among the children surveyed decreased from 30 to 20 per cent. These figures suggest that whereas chronic child undernourishment improved in the surveyed villages in the time frame examined, acute undernourishment deteriorated, reflective of the global food crisis in 2008. Levels of consumption stayed essentially the same, with the mean at 150 Ethiopian birr (roughly 7.5 USD, adjusted for inflation). Mean income levels almost tripled, from 4700 birr to close to 13 thousand birr (230 to 640 USD). There are probably many reasons why this increase did not translate into significantly augmented consumption, with inflation (driving up prices and hence precluding higher consumption) being the key one.

\section{Project Variables}

Based on the theoretical deliberations about project sustainability I have divided the projects in the dataset into five broad categories - unconditional and conditional direct transfers, agricultural and social-infrastructural knowledge transfers, and credit projects. The first category within directtransfer projects contains unconditional transfers of food and cash, while the second one includes conditional cash-for-work and food-for-work programmes. Agricultural knowledge-transfer projects include agricultural extension and irrigation training. The social-infrastructure category of knowledge 
transfers is more varied, ranging from health-extension services through nutrition counselling and family planning to water-well development. Finally, credit projects contain all microfinance activities.

The second part of Table 1 shows that during the first time period, 7 per cent of respondents were receiving unconditional and 29 per cent conditional direct transfers, 9 per cent were beneficiaries of agricultural and 19 per cent of social-infrastructure knowledge-transfer projects, and 22 per cent were participating in credit projects. 34 per cent of surveyed households were not part of any project. In the second time period, the percentage of households receiving unconditional transfers increased to 9 whereas the percentage benefiting from conditional transfers decreased to 23. A slight increase (to 14 per cent) occurred in agricultural projects, a large increase (to 43 per cent) in social-infrastructure projects, and a slight decrease (to 15 per cent) in credit projects. 22 per cent of surveyed households in the second time period were not recipients of any development project.

The rates of households that reported to have benefitted from the different projects in the past are lower than the rates of households currently benefitting from assistance. In 2006, 10 per cent of households claimed to have received conditional and 10 per cent unconditional transfers in the past. These numbers decreased significantly by 2009, to 2 and 5 per cent, respectively. Only 3 per cent of households claimed to have been past participants in agricultural and in social-infrastructure knowledge-transfer projects in 2006, with the number staying the same for agricultural projects and rising to 4 per cent for social-infrastructure projects by the second time period. Finally, 3 per cent of households claimed to have participated in credit projects in 2006 and 15 per cent in 2009.

One of the main takeaway observations from these statistics is that the provision of direct transfers conditioned on work has decreased over time. In contrast, knowledge-transfer projects have become more numerous, with a large increase particularly in the social-infrastructure category. The number of beneficiaries from credit projects has declined from the first to the second time period but the number of past credit beneficiaries indicates that microfinance gained a lot of popularity as a development tool in Ethiopia in the early 2000s. 


\section{Control Variables}

Table 2 reports descriptive statistics for the control variables utilised. Following Strauss and Thomas's (2008) health model, these encompass first the following four categories: children's health inputs, their socio-demographic characteristics, parental and household characteristics, and public health infrastructure. When deciding on specific variables, I looked to already-existing analyses of children's health outcomes in the Young Lives data, primarily to Galab et al. (2006) and Tuan et al. (2006). When using consumption and income levels and not children's nutritional status as the dependent variables, I dropped the children's health-input and public health-infrastructure variables and, inspired by Chen et al. (2009) added several household and community-level variables.

The first category, children's health inputs, comprises each child's subjective birth size as reported by the mother ${ }^{5}$ and a variable that inquires if the child surveyed was born prematurely. Children's socio-demographic characteristics include the age of the child in months and gender (male 1, female 0). Parental and household characteristics contain several variables that characterise the mother of the child in question - her age when the child was born, her highest level of education, whether she is a Muslim, and whether she is of Amhara or Oromo as opposed to Tigrian ethnicityand then a few household-level variables, including whether the household is female-headed, how many members it has, whether it resides in an urban area, and whether it is in the capital city, Addis Ababa. Furthermore, this category includes a household wealth-index. The fourth category, public health infrastructure, inquires whether there is a public health centre/hospital available in the village. Finally, additional income and consumption controls ask whether the head of household has a primary-level education, how far the community where the household resides is from the nearest district capital, how many months a year it is accessible by road, whether it has an adult literacy programme, and whether more than 20 per cent of land within the community is owned by one household.

The descriptive statistics themselves do not provide any particularly surprising information. The mean of the children's subjective birth size is average ( 3 on a scale 1 to 5 ) and 9 per cent of the 
children were born prematurely. The average age of the mother when the child was born is 26 years and her average education achieved is less than three years of school. 28 per cent of the mothers surveyed are of Amhara ethnicity, 21 per cent of Oromo, and the rest are Tigrian. The wealth index does not lend itself to an easy intuitive interpretation but the fact that its mean increased from the first time period to the second suggests that the households surveyed have accumulated more possessions over time. The public health infrastructure data indicate that almost 80 per cent of the people surveyed have a relatively easy access to a public hospital; however, the data do not capture the quality of the facilities available, which might be quite low. Looking at the control variables used with consumption and income levels, in 27 per cent of households the head finished a primaryschool education. Almost half the respondents surveyed live in communities with an adult-literacy programme and 16 per cent in communities where just one household owns more than 20 per cent of all land. Finally, the average distance of the various communities to the closest district capital is $25 \mathrm{~km}$.

\section{Empirical Model and Methods Used}

My aim is to find the average treatment effect of each project type, first during its implementation and second after its cessation, on the treated (ATT). My basic model can thus be expressed as following:

$$
N S_{t}^{j}=\alpha+\beta X_{t}^{j}+\gamma C P_{t}^{j}+\delta E P_{t-1}^{j}+\vartheta^{j}+\varepsilon_{t}^{j}
$$

where NS stands for the nutritional status of recipients children in household $\mathrm{j}$ for time $\mathrm{t}$ (NS can alternatively be substituted with consumption and income levels), $\alpha$ is the constant, $\beta$ is the coefficient of the control variables $X, \gamma$ is the impact of the current projects (CP), $\delta$ is the impact of the projects that have already ended (EP), and finally, $\vartheta^{\mathrm{j}}$ and $\varepsilon_{\mathrm{t}}^{\mathrm{j}}$ are the time-invariant and time-variant components of the error term, respectively.

As with all evaluation researchers, my main challenge is to identify a counterfactual that would most closely resemble the treated group if it had not been treated. One common empirical method 
to do so, the double difference approach, is not applicable to my case as the data do not contain baseline information (prior to the projects' beginning). An approach frequently utilised in such cases is Propensity Score Matching (PSM), a quasi-experimental method based on the construction of a suitable control group to the treated one from untreated households on the basis of observable characteristics. The two key assumptions of the model are:

$$
0<P(X)<1
$$

where $P(X)$ are the propensity scores calculated based on observable variables $X$,

which implies that valid matches on $\mathrm{P}(\mathrm{X})$ can be found for all values of observable variables $\mathrm{X}$ and:

$$
E\left(Y_{t o} \mid X, D=1\right)=E\left(Y_{t o} \mid X, D=0\right)
$$

which presumes that conditional on $\mathrm{X}$, households that did not receive any aid have the same outcomes in the analysed variables as the households that did receive aid would have had they not received it. The PSM approach is in its simple form usually used to analyse cross-sectional data and my data are panel. Thus, I use a panel-data PSM approach described by Nguyen Viet (2010).

In order to elucidate this approach, let $D_{1}$ and $D_{2}$ denote the project intervention status within the first and the second time period in my dataset, respectively. $Y_{1 F}$ and $Y_{0 F}$ stand for outcomes with and without the intervention in the first period and $Y_{15}$ and $Y_{0 s}$ in the second time period. I am interested in the ATT in the second period, which can be expressed as the following:

$$
A T T_{X}^{S}=E\left(Y_{1 S} / X, D 2=1\right)-E\left(Y_{0 S} \mid X, D 2=1\right)
$$

Since I cannot observe the second term, the equation can be re-written as following: 


$$
\begin{aligned}
& A T T_{X}^{S}=\operatorname{Pr}\left(D_{1}=1 / X, D_{2}=1\right)\left[E\left(Y_{1 S} \mid X, D_{1}=1, D_{2}=1\right)-E\left(Y_{\text {oS }} \mid X, D_{1}=1, D_{2}=1\right)\right]+ \\
& \operatorname{Pr}\left(D_{0}=1 / X, D_{2}=1\right)\left[E\left(Y_{1 S} \mid X, D_{1}=0, D_{2}=1\right)-E\left(Y_{\text {oS }} \mid X, D_{1}=0, D_{2}=1\right)\right]
\end{aligned}
$$

Two additional assumptions added to this equation are that the difference in the nonintervention outcomes, conditional on $\mathrm{X}$, between people who did not participate in the project in either period and those who participated only in the second period has remained constant overtime. The second assumption is that the difference between the non-intervention outcomes in the first period has been the same for people who participated in the intervention in both periods and those who participated in the project in the first period but not in the second one. With the addition of these assumptions, equation 2 can be re-written in the following manner:

$$
\begin{aligned}
& A T T_{X}^{S}=\operatorname{Pr}\left(D_{1}=1 \mid X, D_{2}=1\right)\left\{\left[E\left(Y_{1 S} \mid X, D_{1}=1, D_{2}=1\right)-E\left(Y_{O S} \mid X, D_{1}=1, D_{2}=0\right)\right]-\left[E \left(Y_{1 F} \mid X,\right.\right.\right. \\
& \left.\left.\left.D_{1}=1, D_{2}=1\right)-E\left(Y_{1 F} \mid X, D_{1}=1, D_{2}=0\right)\right]\right\}+\operatorname{Pr}\left(D_{1}=0 / X, D_{2}=1\right)\left\{\left[E\left(Y_{1 S} \mid X, D_{1}=0, D_{2}=1\right)-\right.\right. \\
& \left.\left.E\left(Y_{O S} \mid X, D_{1}=0, D_{2}=0\right)\right]-\left[E\left(Y_{O F} \mid X, D_{1}=0, D_{2}=1\right)-E\left(Y_{O F} \mid X, D_{1}=0, D_{2}=0\right)\right]\right\}
\end{aligned}
$$

where all terms can now be observed. Matching is then be performed between: 1 . the people who were project recipients in both periods and those who were recipients only in the first period and 2 . the people who were project recipients only in the second period and those who did not receive project benefits at all, in either time period.

This approach is first separately applied to each of the project types, in which households were participating at the time of the data collection, controlling for the other four types of projects, which some households were receving concurrently. In order to find out the effects of the projects after their cessation, this process is then repeated for project variables that capture only the projects that have ended already. Both the other types of completed projects and also all the current projects are added as controls into the equations that calculate the propensity scores used for matching. In each 
equation, I use three different types of matching - the nearest-neighbour, the five-nearestneighbours, and the Kernel approach.

As a robustness check, I employ regular panel OLS regressions. Their advantage is that they can fit all the different project variables, both current and past, into one model ${ }^{6}$. The first estimator used here is the panel regression with fixed effects, which has the added benefit of eliminating any potential bias arising from time-invariant unobservable characteristics (regular for continuous dependent variables, logit for binary ones). The main upside of the second estimators, the HausmanTaylor regression for continuous variables and logit regressions with random-effects for binary ones, is the possible inclusion of time-invariant control variables (which are eliminated from the fixedeffects regression). The Hausman-Taylor regressions have also the potential to control for the possible endogeneity of the projects resulting from selection bias ${ }^{7}$. The obvious downside of the OLS estimators is that they do not belong among those standardly used in impact evaluation, which is also why they are only utilised to assess the validity of the results obtained through the PSM.

As with any project evaluation, there is a need to think about the potential spill-over of the project results. In my study, this worry is particularly relevant to knowledge-transfer projects, as neither direct-transfer nor credit projects' achievements can be adopted by control groups without further external input, whereas the skills passed on by knowledge-transfer projects can 'spill over' relatively easily. The Young Lives data on project support are not detailed enough to control for this issue empirically; the best I can do then is to keep in mind when evaluating the results achieved on knowledge-transfer projects that their effects might actually be underestimated.

\section{Results}

Table 3 shows results of the PSM equations. The first part of the table displays coefficients for the variables that capture the short-term effect of participation in the five different types of projects. The most consistently significant project type here is the agricultural knowledge-transfer one, which raises consumption levels and decreases the rates of underweight and stunted children. 
Unconditional direct transfers also decrease the rates of underweight children while simultaneously - and surprisingly - decreasing consumption levels. The latter, seemingly counterintuitive, finding can be explained by the fact that those who receive free food buy consequently less but at the same time might not report food aid when asked about consumption. Conditional direct transfers, on the other hand, increase people's incomes but this augmentation has not translated into raised consumption or into improvements in children's nutritional status.

Results in the lower half of the table capture the long-term effects of the projects. Agricultural knowledge-transfers have an impact on children's nutritional status beyond their duration, reducing children's underweight and under-BMI rates even in the longer term; however, they have no longer any impact on household consumption levels. Unconditional direct transfers reduce rates of under$\mathrm{BMI}$ in the longer run, whereas conditional transfers still increase income levels. Social-infrastructure projects, which appeared insignificant during their lifetime, reduce the prevalence of underweight and under-BMI children post-cessation, suggesting a delayed positive effect on children's nutritional outcomes. Finally, credit projects appear insignificant both throughout and following their duration.

Table 4 displays the results obtained when using panel OLS regressions as a robustness check. The major findings remain the same. Agricultural knowledge transfer projects improve children's nutritional outcomes both during and after project implementation. Unconditional transfers have the same albeit weaker impact (only on rates of under-BMI children). Conditional direct transfers increase income levels but have no impact on children's nutritional status, save from one regression model where they do appear to reduce the rate of child stunting. Social knowledge transfers reduce the prevalence of under-BMI children some years after they have been implemented. Lastly, credit projects, which in the PSM model were insignificant, seem to lower incomes in the short run while raising consumption in the longer run.

From the control variables included, the most consistently significant are children's birth size, their age in months, mothers' education level, and the household wealth index, all contributing to lower undernourishment rates. A household head having completed primary education, a village's 
proximity to a district capital, and accessibility all increase income and consumption levels. Lastly, being of Oromo ethnicity and living in Addis Ababa both factor into lower prevalence of child stunting and being underweight and into higher income and consumption.

\section{Discussion}

Overall, across the various specifications, a few key results stand out. First, agricultural knowledge-transfer projects have the strongest positive impact on recipients' wellbeing both during their implementation and beyond it. During their lifetime, these projects bolster recipients' consumption levels, although without raising their incomes - probably because they contribute to higher food availability in the household, which is counted towards consumption but not towards income levels. This raised consumption translates into lower prevalence of underweight and stunted children among the projects' households. After the projects have finished, they continue to lower the rates of underweight and under-BMI children; however, they no longer have a significant impact on child stunting, which is a more long-term measure of nutritional status than the other two. This finding suggests that although the projects' results last beyond their lifetime and are, hence, sustainable to some extent, their positive impact does wane with time.

In contract, social-infrastructure knowledge-transfer projects have no impact on recipients throughout their duration but they do lower the rates of underweight and under-BMI children after they have ended, approximately to the same extent as agricultural knowledge-transfer projects. Since social-infrastructure projects include activities such as nutritional counselling and hygiene education, it is not surprising that their positive effects on recipients' nutritional status become evident only in the longer time horizon. However, it is difficult to evaluate on the basis of this study how truly 'sustainable' their impact is. The projects reported as discontinued in the dataset all finished within the five-year period prior to data collection and hence it is impossible to know whether any effect would be apparent ten or fifteen years post-project. 
The findings vis-à-vis direct transfers are less in line with my original hypotheses. I expected to find both unconditional and conditional direct transfers to be supportive of children's nutritional status as well as of household consumption levels in the short-run but probably not in the long-run. Unconditional direct transfers do strengthen children's nutritional status in the short term but only mildly so. At the same time, however, they have a positive effect on children's BMI even after they have been discontinued, which optimistically indicates that the positive effects of this type of projects are more lasting than originally imagined ${ }^{8}$. The more confusing results were with regard to conditional transfers, which raise household incomes both in the short and in the long run but were found to have no effect on any of the other indicators examined. The most likely explanation for why higher income does not translate into improvements in consumption levels and nutritional outcomes is that the households used the additional income to create savings. However, the existing data are not able to clarify why precisely that has been the case, pointing to a need for a more indepth, explorative study of the issue.

Finally, credit projects in this study appear to have had no consistently significant effect on recipients' incomes, consumption, or children's nutritional status, whether in the short or in the long run. This finding goes against my hypothesis, as many researchers concluded that credit projects strengthened recipients' wellbeing to some extent. At the same time, this is not the first paper to find that a particular microfinance project had no impact (e.g. Barnes et al., 2001) and it by no means denotes the ineffectiveness of credit projects generally. In order to elucidate more clearly why these projects have been ineffective here, an in-depth field study would again be needed.

\section{Conclusions}

The data used in this study have several drawbacks, which limit the range of conclusions that can be made vis-à-vis the 'sustainability' of different types of development projects administered throughout Ethiopia. Hence, the main, and relatively modest, conclusion is that knowledge-transfer projects have a greater positive impact on household consumption levels and children's nutritional 
outcomes than direct-transfer projects in the longer term and, more surprisingly, in the case of agricultural projects also in the short term. This finding suggests that agricultural extension and training projects might be a better tool for reducing food insecurity and poverty than direct transfers even in the immediate time horizon. Another important take-away point from this paper is that social-infrastructure projects appeared to have no impact on recipients in the short run but turned out to affect outcome indicators positively several years after implementation, a deferred positive effect that could easily be missed if impact evaluations were carried out too soon.

The study has also uncovered some questions worthy of further consideration. First, it indicated that unconditional direct transfers had an easier time translating into poverty-reducing outcomes than conditional transfers, whose resultant increase in incomes had no follow-up effect on consumption or nourishment. Second, it showed that microfinance projects among the households surveyed had no positive impact on recipients, a somewhat unusual result in light of the existing literature on the effectiveness of credit projects. Both these points should be examined further using more in-depth, qualitative research tools. The 2015 round of Young Lives data collection, which will be complemented by qualitative research methods including long interviews, could be instrumental in this endeavour.

\footnotetext{
${ }^{1}$ The logical connection here is quite clear - raised consumption levels are likely to result in lower child undernourishment rates. Even raised income levels alone should decrease child malnutrition levels, as parents will often use any extra funds to provide better/more food to their offspring (Carter and Maluccio, 2003).

${ }^{2}$ More information can be found at younglives.org.uk.

${ }^{3}$ However, data on some time-invariant variables used, such as for example on whether a child was born prematurely, come from round one of data collection.

${ }^{4}$ Children with Z-scores lower than negative two on weight-for-age are lighter for their age than 95 per cent of their national cohort peers, which the WHO has defined as moderate to severe undernourishment. The same is true of children with Z scores below negative two on height-for-age and BMI-for-age.

${ }^{5}$ Birth size ranges from 1 for a very small to 5 for a very large baby (subjective measure).

${ }^{6} \mathrm{~A}$ VIF measure showed that there was no co-linearity present among the different project variables.

${ }^{7}$ Both estimators include robust standard errors.
} 
${ }^{8}$ However, since these results reflect only a short time-period and focus on the household level, they cannot capture the potentially negative effects of continuous food transfers on Ethiopian food production and food security. 


\section{References}

Anand S, Sen A. 2000. Human development and economic sustainability. World Development 28(12): 2029-2049.

Alderman H, Behrman JR, Lavy V, Menon R. 2001. Child health and school enrolment: A longitudinal analysis. Journal of Human Resource 36(1): 185-205.

Baird S, McIntosh C, Özler B. 2011. Cash or condition? Evidence from a cash transfer experiment. The Quarterly Journal of Economics 12(64): 1709-1753.

Barnes C, Keogh E, Nemarundwe N. 2001. Microfinance program clients and impact: An assessment of Zambuko Trust, Zimbabwe. AIMS: Washington, DC.

Barrett CB. 2002. Food security and food assistance programs. Handbook of Agricultural Economics 2: 2103-2190.

Berhane G, Gardebroek C. 2012. Assessing the Long-term Impact of Microcredit on Rural Poverty: Does the Timing and Length of Participation Matter? ESSP // Working Paper, International Food Policy Research Institute.

Berti PR, Krasevec J, FitzGerald S. 2004. A review of the effectiveness of agriculture interventions in improving nutrition outcomes. Public Health Nutrition 7(5): 599-609.

Bhutta ZA, Ahmed T, Black RE, Cousens S, Dewey K, Giugliani E, Haider BA, Kirkwood B, Morris SS, Sachdev HP, Shekar M. 2008. What works? Interventions for maternal and child undernutrition and survival. The Lancet 371(9610): 417-440.

Carter MR, Maluccio JA. 2003. Social Capital and Coping with Economic Shocks: An Analysis of Stunting of South African Children. World Development Report 317: 1147-1163.

Chen S, Mu R, Ravallion M. 2009. Are there lasting impacts of aid to poor areas? Journal of Public Economics 93(3): 512-528.

Copestake J, Bhalotra S, and Johnson S. 2001. Assessing the impact of microcredit: A Zambian case study. Journal of Development Studies 37(4): 81-100. 
De Graaf M. 1986. Catching fish or liberating man: social development in Zimbabwe. Journal of Social Development in Africa 1(1): 7-26.

Development Assistance Committee. 2013. Query Wizard for International Development Statistics. Accessed from: http://stats.oecd.org/qwids/, Aug 5.

Food and Agriculture Organization. 2012. The State of Food Insecurity in the World 2012. Rome: FAO.

Fiallos E, Ruiz Cantero MT. 2008. ¿A quién benefician los programas de salud dirigidos a los más pobres? Éxitos y fracasos. Gaceta Sanitaria 22: 230-236.

Galab S, Piush A, Wilson I, Jones N, McCoy A, Rama Raju DS, Reddy P. 2006. Exploring linkages between maternal social capital and children's nutritional status in Andhra Pradesh. Young Lives Working Paper, No. 32.

Gelan AU. 2007. Does food aid have disincentive effects on local production? A general equilibrium perspective on food aid in Ethiopia. Food Policy 32(4): 436-458.

Gibson A. 1993. NGOs and income-generation projects: lessons from the Joint Funding Scheme. Development in Practice 3(3): 184-195.

Grantham-McGregor S. 1995. A review of studies of the effect of severe malnutrition on mental development. The Journal of Nutrition 125(8): $2233 \mathrm{~S}$.

Gilligan DO, Hoddinott J. 2007. Is there persistence in the impact of emergency food aid? Evidence on consumption, food security, and assets in rural Ethiopia. American Journal of Agricultural Economics 89(2): 225-242.

Gilligan DO, Hoddinott J, Taffesse AS. 2009. The impact of Ethiopia's Productive Safety Net Programme and its linkages. The Journal of Development Studies 45(10): 1684-1706.

Hoque BA, Juncker T, Sack RB, Ali M, Aziz KM. 1996. Sustainability of a water, sanitation and hygiene education project in rural Bangladesh: a 5-year follow-up. Bulletin of the World Health Organization 74(4): 431.

Imai KS, Azam MS. 2012. Does microfinance reduce poverty in Bangladesh? New evidence from household panel data. Journal of Development Studies 48(5): 633-653. 
Infant and Young Child Nutrition Project. 2011. Nutrition and Food Security Impacts of Agriculture Projects. USAID: Washington, DC.

Kremer M. 2003. Randomized evaluations of educational programs in developing countries: Some lessons. The American Economic Review 93(2): 102-106.

Nguyen Viet C. 2012. A Matching Method with Panel Data. Statistics in Medicine 32: 577-588.

White JM, Mason JB. 2012. Assessing the impact on child nutrition of the Ethiopia Community-based Nutrition Program. Report to UNICEF of an evaluation study. Tulane SPHTM/UNICEF: Addis Ababa, Ethiopia.

Panjaitan RD, Cloud K. 1999. Gender, self-employment and microcredit programs: An Indonesian case study. The Quarterly Review of Economics and Finance 39(5): 769-779.

Quisumbing AR. 2003. Food aid and child nutrition in rural Ethiopia. World Development 31(7): 13091324.

Samson M. 2006. Are conditionalities necessary for human development? In Third International Conference on Conditional Cash Transfer, 26-30.

Schrieder G, Sharma M. 1999. Impact of Finance on Poverty Reduction and Social Capital Formation. Savings and Development 23(1): 67-93.

Strauss J, Thomas D. 2008. Health over the Life Course. Handbook of Development Economics 4(5): $3375-3474$.

Tadesse G, Shively G. 2009. Food aid, food prices, and producer disincentives in Ethiopia. American Journal of Agricultural Economics 91(4): 942-955.

Taylor B. 2013. Who Wants to Give Forever? Giving Meaning to Sustainability in Development. Paper presented at the Annual DSA Conference in Birmingham, UK on 16 November.

Tuan T, Harpham T, De Silva M, Thu Huong N, Tod B, Thi Lan P, Duc Thach T, Abeyasekera S. 2006. Maternal Social Capital and Child Health in Vietnam. Young Lives Working Paper, No. 30. 
World Development Indicators (WDI). 2013. World Bank. Accessed from: http://data.worldbank.org/data-catalog/world-development-indicators, Aug 5, 2013.

World Food Programme (WFP). 2013. 10 Things Everyone Should Know about Hunger in Ethiopia. Accessed from: http://www.wfp.org/stories/10-things-everyone-should-know-about-hungerethiopia, Aug 5, 2013.

World Health Organization (WHO). 2006. WHO Child Growth Standards: Length/Height-for-age, Weight-for-age, Weight-for-length, Weight-for-height and Body Mass Index-for-age. Methods and Development. 


\section{Tables}

Table 1. Descriptive Statistics for Outcome and Project Variables

\begin{tabular}{|c|c|c|c|c|c|c|c|c|}
\hline \multirow[b]{2}{*}{ Variable } & \multicolumn{4}{|c|}{ TIME PERIOD ONE } & \multicolumn{4}{|c|}{ TIME PERIOD TWO } \\
\hline & Mean & St Dev & Min & Max & Mean & St Dev & Min & Max \\
\hline \multicolumn{9}{|l|}{ Outcome Indicators } \\
\hline \multicolumn{9}{|l|}{ Nutrition Variables } \\
\hline Underweight children (prevalence) & 0.23 & 0.42 & 0 & 1 & 0.32 & 0.47 & 0 & 1 \\
\hline Stunted children (prevalence) & 0.30 & 0.46 & 0 & 1 & 0.20 & 0.40 & 0 & 1 \\
\hline Under-BMI children (prevalence) & 0.08 & 0.27 & 0 & 1 & 0.20 & 0.40 & 0 & 1 \\
\hline \multicolumn{9}{|l|}{ Secondary Outcome Indicators } \\
\hline Consumption levels (monthly, in Eth birr) & 150 & 110 & -142 & 1142 & 150 & 110 & 20 & 1142 \\
\hline Income (annual, in Eth birr) & 4724 & 16462 & 0 & 565000 & 12818 & 96370 & & 4050000 \\
\hline \multicolumn{9}{|l|}{ Project Types } \\
\hline \multicolumn{9}{|l|}{ Ongoing } \\
\hline Unconditional direct transfers & 0.07 & 0.26 & 0 & 1 & 0.09 & 0.29 & 0 & 1 \\
\hline Conditional direct transfers & 0.29 & 0.46 & 0 & 1 & 0.23 & 0.42 & 0 & 1 \\
\hline Agricultural transfers & 0.09 & 0.28 & 0 & 1 & 0.14 & 0.35 & 0 & 1 \\
\hline Social knowledge transfers & 0.19 & 0.39 & 0 & 1 & 0.43 & 0.49 & 0 & 1 \\
\hline Credit projects & 0.22 & 0.41 & 0 & 1 & 0.15 & 0.36 & 0 & 1 \\
\hline \multicolumn{9}{|l|}{ Finished } \\
\hline Unconditional direct transfers & 0.10 & 0.30 & 0 & 1 & 0.02 & 0.14 & 0 & 1 \\
\hline Conditional direct transfers & 0.10 & 0.30 & 0 & 1 & 0.05 & 0.42 & 0 & 1 \\
\hline Agricultural transfers & 0.03 & 0.08 & 0 & 1 & 0.03 & 0.08 & 0 & 1 \\
\hline Social knowledge transfers & 0.03 & 0.10 & 0 & 1 & 0.04 & 0.19 & 0 & 1 \\
\hline Credit projects & 0.03 & 0.17 & 0 & 1 & 0.15 & 0.36 & 0 & 1 \\
\hline $\mathrm{N}$ & \multicolumn{4}{|c|}{1853} & \multicolumn{4}{|c|}{1748} \\
\hline
\end{tabular}

Source: Author's own calculations 
Table 2. Descriptive Statistics for Control Variables

\begin{tabular}{|c|c|c|c|c|c|c|c|c|}
\hline \multirow[b]{2}{*}{ Variable } & \multicolumn{4}{|c|}{ TIME PERIOD ONE } & \multicolumn{4}{|c|}{ TIME PERIOD TWO } \\
\hline & Mean & St Dev & Min & Max & Mean & St Dev & Min & Max \\
\hline \multicolumn{9}{|l|}{ Health Inputs } \\
\hline Birth size & 3.00 & 1.02 & 1 & 5 & 2.99 & 1.02 & 1 & 5 \\
\hline Premature & 0.09 & 0.29 & 0 & 1 & 0.09 & 0.28 & 0 & 1 \\
\hline \multicolumn{9}{|l|}{ Socio-Demographic Characteristics } \\
\hline Child's gender (male) & 0.53 & 0.50 & 0 & 1 & 0.52 & 0.50 & 0 & 1 \\
\hline Child's age (in months) & 62.31 & 3.79 & 52.83 & 75.42 & 97.40 & 4.03 & 86.30 & 138.38 \\
\hline \multicolumn{9}{|l|}{ Parental/Household Characteristics } \\
\hline Mother's age when child born & 27.52 & 6.31 & 15 & 55 & 27.61 & 6.32 & 15 & 55 \\
\hline Mother's highest education & 2.74 & 3.74 & 0 & 14 & 2.64 & 3.67 & 0 & 14 \\
\hline Mother of Amhara ethnicity & 0.28 & 0.45 & 0 & 1 & 0.28 & 0.45 & 0 & 1 \\
\hline Mother of Oromo ethnicity & 0.21 & 0.40 & 0 & 1 & 0.20 & 0.40 & 0 & 1 \\
\hline Mother a Muslim & 0.16 & 0.37 & 0 & 1 & 0.17 & 0.38 & 0 & 1 \\
\hline Female-headed hh & 0.13 & 0.34 & 0 & 1 & 0.13 & 0.34 & 0 & 1 \\
\hline HH size & 6.09 & 2.08 & 2 & 16 & 6.27 & 1.97 & 2 & 14 \\
\hline Urban & 0.39 & 0.52 & 0 & 1 & 0.38 & 0.53 & 0 & 1 \\
\hline Addis Ababa & 0.15 & 0.36 & 0 & 1 & 0.14 & 0.35 & 0 & 1 \\
\hline Wealth index & 0.28 & 0.18 & 0.01 & 0.87 & 0.32 & 0.17 & 0.01 & 0.86 \\
\hline \multicolumn{9}{|l|}{ Public Health Indicators } \\
\hline Public health clinic in village & 0.80 & 0.40 & 0 & 1 & 0.80 & 0.40 & 0 & 1 \\
\hline \multicolumn{9}{|l|}{ Additional Consumption and Income Controls } \\
\hline HH head primary education & 0.27 & 0.44 & 0 & 1 & 0.27 & 0.45 & 0 & 1 \\
\hline Distance to closest town (in kms) & 25.62 & 40.60 & 0 & 180 & 26.62 & 41.13 & 0 & 180 \\
\hline Village accessible $\mathrm{x}$ months a year by road & 11.36 & 0.99 & 8 & 12 & 11.34 & 0.96 & 8 & 12 \\
\hline Village has an adult literacy course & 0.47 & 0.50 & 0 & 1 & 0.47 & 0.49 & 0 & 1 \\
\hline More than $20 \%$ land in village owned by one $\mathrm{HH}$ & 0.16 & 0.36 & 0 & 1 & 0.17 & 0.37 & 0 & 1 \\
\hline $\mathrm{N}$ & \multicolumn{4}{|c|}{1853} & \multicolumn{4}{|c|}{1748} \\
\hline
\end{tabular}

Source: Author's own calculations 
Table 3. PSM Results for Children's Nutritional Outcomes, Consumption, and Income Levels

\begin{tabular}{|c|c|c|c|c|c|c|c|c|c|c|c|c|c|c|c|}
\hline \multirow{2}{*}{$\begin{array}{l}\text { Outcome Variable } \\
\text { PSM Approach }\end{array}$} & \multicolumn{3}{|c|}{ Underweight } & \multicolumn{3}{|c|}{ Stunted } & \multicolumn{3}{|c|}{ Under-BMI } & \multicolumn{3}{|c|}{ Consumption } & \multicolumn{3}{|c|}{ Income } \\
\hline & $N N$ & $5 N N$ & Kernel & $N N$ & $5 N N$ & Kernel & $N N$ & $5 N N$ & Kernel & $N N$ & $5 N N$ & Kernel & $N N$ & $5 N N$ & Kernel \\
\hline \multirow[t]{2}{*}{ Unconditional direct transfers (ongoing) } & -0.04 & -0.05 & -0.05 & -0.02 & -0.01 & 0.02 & 0.00 & 0.00 & -0.01 & -8.77 & -15.1 & -15.4 & 0.07 & -0.06 & -0.09 \\
\hline & 1.59 & 1.71 & 1.77 & 0.54 & 0.28 & 0.53 & 0.11 & 0.17 & 0.51 & 0.74 & 2.20 & 1.94 & 0.45 & 0.45 & 0.73 \\
\hline \multirow[t]{2}{*}{ Conditional direct transfers (ongoing) } & -0.01 & 0.02 & 0.01 & 0.02 & 0.02 & 0.02 & -0.02 & -0.01 & -0.01 & -2.72 & -2.26 & -3.23 & 0.23 & 0.23 & 0.24 \\
\hline & 0.17 & 0.60 & 0.21 & 0.72 & 0.73 & 0.76 & 0.66 & 0.33 & 0.78 & 0.45 & 0.39 & 0.95 & 2.40 & 3.13 & 3.40 \\
\hline \multirow[t]{2}{*}{ Agricultural transfers (ongoing) } & -0.09 & -0.08 & -0.09 & -0.09 & -0.07 & -0.09 & -0.01 & -0.02 & -0.01 & 15.3 & 14.2 & 12.8 & -0.11 & -0.09 & -0.05 \\
\hline & 2.38 & 2.73 & 3.41 & 2.59 & 2.63 & 3.43 & 0.48 & 0.79 & 0.65 & 2.69 & 3.07 & 2.83 & 1.03 & 1.09 & 0.68 \\
\hline \multirow[t]{2}{*}{ Social knowledge transfers (ongoing) } & 0.02 & 0.00 & 0.01 & 0.04 & 0.03 & 0.03 & -0.03 & -0.03 & -0.02 & -14.4 & -12.8 & -9.87 & -0.15 & -0.08 & -0.10 \\
\hline & 0.79 & 0.13 & 0.45 & 1.59 & 1.51 & 1.60 & 1.24 & 1.50 & 1.54 & 1.39 & 1.32 & 1.20 & 1.49 & 1.25 & 1.28 \\
\hline \multirow[t]{2}{*}{ Credit projects (ongoing) } & -0.03 & -0.01 & 0.00 & -0.04 & -0.02 & -0.02 & 0.01 & 0.01 & 0.01 & 3.28 & -1.21 & 0.75 & 0.03 & -0.05 & -0.06 \\
\hline & 0.80 & 0.41 & 0.02 & 1.35 & 1.05 & 1.12 & 0.05 & 0.06 & 0.45 & 0.50 & 0.23 & 0.16 & 0.30 & 1.20 & 1.35 \\
\hline \multirow[t]{2}{*}{ Unconditional direct transfers (past) } & 0.06 & 0.04 & 0.06 & 0.06 & 0.02 & 0.05 & -0.18 & -0.07 & -0.07 & -9.54 & -10.3 & -7.42 & -0.85 & -0.69 & -0.62 \\
\hline & 0.83 & 0.55 & 0.93 & 1.03 & 0.56 & 0.82 & 3.71 & 2.17 & 2.54 & 1.05 & 1.14 & 0.10 & 3.54 & 4.12 & 5.47 \\
\hline \multirow[t]{2}{*}{ Conditional direct transfers (past) } & 0.05 & 0.04 & 0.04 & 0.05 & 0.02 & 0.01 & -0.01 & -0.02 & -0.01 & -1.90 & -1.95 & -1.85 & 0.28 & 0.35 & 0.32 \\
\hline & 1.23 & 1.07 & 1.13 & 1.21 & 0.52 & 0.17 & 0.15 & 0.65 & 0.35 & 0.32 & 0.35 & 0.28 & 2.24 & 3.31 & 3.31 \\
\hline \multirow[t]{2}{*}{ Agricultural transfers (past) } & -0.08 & -0.08 & -0.08 & -0.06 & -0.04 & -0.06 & -0.08 & -0.08 & -0.09 & 1.16 & 1.70 & 5.43 & -0.68 & -0.57 & -0.54 \\
\hline & 1.89 & 1.73 & 1.85 & 1.56 & 1.12 & 1.49 & 1.92 & 1.90 & 2.08 & 0.05 & 0.14 & 1.20 & -1.48 & 1.48 & 1.55 \\
\hline \multirow[t]{2}{*}{ Social knowledge transfers (past) } & -0.08 & -0.07 & -0.08 & -0.02 & -0.01 & -0.03 & -0.11 & -0.07 & -0.07 & -8.30 & -9.80 & -2.25 & 0.07 & 0.09 & 0.12 \\
\hline & -1.69 & -1.58 & 1.86 & 0.36 & 0.20 & 0.82 & 1.98 & 1.87 & 1.94 & 0.40 & 0.68 & 0.18 & 0.32 & 0.58 & 0.85 \\
\hline \multirow[t]{2}{*}{ Credit projects (past) } & -0.02 & -0.04 & -0.04 & 0.05 & 0.02 & 0.03 & 0.00 & 0.02 & 0.03 & 0.22 & 1.58 & 1.47 & 0.02 & 0.02 & 0.02 \\
\hline & 0.35 & 1.17 & 1.20 & 1.18 & 0.60 & 0.92 & 0.01 & 0.60 & 0.96 & 0.02 & 0.19 & 0.20 & 0.14 & 0.20 & 0.17 \\
\hline
\end{tabular}

Numbers next to variables represent the Average Treatment on the Treated ATT) coefficients, numbers below are T Statistics. Numbers in bold are significant at least at the 10 per cent level. 
Table 4. OLS Results for Children's Nutritional Outcomes, Consumption, and Income Levels

\begin{tabular}{|c|c|c|c|c|c|c|c|c|c|c|}
\hline \multirow{2}{*}{$\begin{array}{l}\text { Variable } \\
\text { OLS Approach }\end{array}$} & \multicolumn{2}{|c|}{ Underweight } & \multicolumn{2}{|c|}{ Stunted } & \multicolumn{2}{|c|}{ Under-BMI } & \multicolumn{2}{|c|}{ Consumption } & \multicolumn{2}{|c|}{ Income } \\
\hline & $F E$ & $R E$ & $F E$ & $R E$ & $F E$ & $R E$ & $F E$ & $H T$ & $F E$ & $H T$ \\
\hline \multirow[t]{2}{*}{ Unconditional direct transfers (current) } & 0.14 & 0.01 & 0.38 & 0.24 & -0.84 & -0.93 & -0.28 & -0.37 & -0.10 & -0.13 \\
\hline & 0.29 & 0.02 & 1.01 & 0.86 & 1.71 & 1.79 & 0.33 & 0.42 & 0.74 & 1.03 \\
\hline \multirow[t]{2}{*}{ Conditional direct transfers (current) } & -0.37 & -0.24 & 0.28 & 0.12 & 0.09 & -0.14 & -0.79 & -0.79 & -0.03 & -0.03 \\
\hline & 0.85 & 0.83 & 0.61 & 0.44 & 0.20 & 0.48 & 1.18 & 1.16 & 1.08 & 1.21 \\
\hline \multirow[t]{2}{*}{ Agricultural transfers (current) } & -1.07 & -1.06 & 0.48 & 0.02 & -0.43 & -0.48 & 0.83 & 0.84 & 0.15 & 0.14 \\
\hline & 3.42 & 4.28 & 1.28 & 0.07 & 1.81 & 2.07 & 1.49 & 1.56 & 1.57 & 1.55 \\
\hline \multirow[t]{2}{*}{ Social knowledge transfers (current) } & -0.04 & 0.25 & -0.28 & -0.18 & 0.00 & -0.18 & -0.34 & -0.39 & 0.20 & 0.19 \\
\hline & 0.14 & 1.37 & 1.06 & 0.98 & 0.01 & 1.08 & 0.69 & 0.79 & 1.63 & 1.62 \\
\hline \multirow[t]{2}{*}{ Credit projects (current) } & 0.39 & 0.43 & 0.25 & -0.12 & 0.23 & 0.32 & 0.17 & 0.23 & -0.40 & -0.37 \\
\hline & 1.49 & 1.59 & 0.56 & 0.44 & 0.62 & 1.22 & 0.24 & 0.33 & 3.64 & 3.70 \\
\hline \multirow[t]{2}{*}{ Unconditional direct transfers (current) } & -0.09 & 0.02 & 0.13 & 0.99 & -0.82 & -1.16 & 0.18 & 0.31 & -0.06 & -0.06 \\
\hline & 0.22 & 0.08 & 0.31 & 3.31 & 1.73 & 2.88 & 0.22 & 0.37 & 1.60 & 1.54 \\
\hline \multirow[t]{2}{*}{ Conditional direct transfers (past) } & 0.28 & 0.29 & -0.32 & -0.47 & 0.34 & 0.13 & -0.37 & -0.48 & 0.42 & 0.40 \\
\hline & 0.80 & 1.30 & 0.85 & 2.02 & 0.88 & 0.69 & 0.50 & 0.64 & 3.67 & 3.79 \\
\hline \multirow[t]{2}{*}{ Agricultural transfers (past) } & -1.77 & -1.83 & 0.42 & -0.06 & -0.70 & -0.43 & -0.31 & -0.26 & -0.03 & -0.02 \\
\hline & 1.74 & 1.75 & 0.25 & 0.07 & 0.61 & 0.57 & 0.13 & 0.11 & 0.08 & 0.06 \\
\hline \multirow[t]{2}{*}{ Social knowledge transfers (past) } & -0.36 & -0.39 & -0.11 & -0.38 & -1.11 & -0.97 & -0.47 & -0.50 & 0.06 & 0.05 \\
\hline & 0.50 & 0.74 & 0.15 & 0.71 & 1.68 & 1.65 & 0.31 & 0.33 & 0.27 & 0.23 \\
\hline \multirow[t]{2}{*}{ Credit projects (past) } & 0.23 & -0.12 & 0.65 & 0.22 & -0.22 & 0.06 & 1.37 & 1.39 & 0.18 & 0.19 \\
\hline & 0.53 & 0.47 & 1.61 & 0.84 & 0.46 & 0.28 & 1.74 & 1.74 & 1.48 & 1.67 \\
\hline \multirow[t]{2}{*}{ Birth size } & & -0.39 & & -0.16 & & -0.25 & & & & \\
\hline & & 3.64 & & 1.51 & & 3.18 & & & & \\
\hline \multirow[t]{2}{*}{ Child's age (in months) } & 0.05 & 0.04 & 0.04 & 0.03 & 0.05 & 0.05 & & & & \\
\hline & 6.80 & 9.15 & 6.02 & 5.55 & 8.08 & 9.50 & & & & \\
\hline \multirow[t]{2}{*}{ Mother's highest education } & & -0.12 & & -0.08 & & -0.07 & & 7.86 & & 0.02 \\
\hline & & 3.14 & & 2.09 & & 1.96 & & 9.51 & & 2.25 \\
\hline \multirow[t]{2}{*}{ Mother of Oromo ethnicity } & & -0.60 & & 0.36 & & -0.43 & & 32.09 & & 0.23 \\
\hline & & 2.08 & & 1.31 & & 1.91 & & 5.48 & & 2.92 \\
\hline Household size & 0.20 & 0.10 & 0.06 & 0.00 & 0.11 & 0.04 & -0.24 & -0.41 & -0.07 & -0.06 \\
\hline & 1.84 & 1.94 & 0.10 & 0.04 & 1.07 & 1.04 & 1.13 & 1.95 & 2.16 & 4.19 \\
\hline Addis Ababa & & -0.26 & & -0.67 & & 0.53 & & 10.89 & & 0.55 \\
\hline & & 0.71 & & 1.80 & & 1.40 & & 1.64 & & 4.02 \\
\hline Wealth index & -3.31 & -6.60 & -3.00 & -3.62 & -2.25 & -1.73 & 4.38 & 5.45 & 1.75 & 2.60 \\
\hline & 2.21 & 8.56 & 1.98 & 4.71 & 1.73 & 2.79 & 1.83 & 1.90 & 3.95 & 11.75 \\
\hline Public health clinic in village & 0.08 & -1.06 & -0.47 & -0.86 & 0.87 & -0.45 & & & & \\
\hline & 0.14 & 4.17 & 1.03 & 3.42 & 1.30 & 2.36 & & & & \\
\hline HH head primary education & & & & & & & & 21.23 & & 0.14 \\
\hline & & & & & & & & 3.39 & & 1.68 \\
\hline Distance to district capital & & & & & & & & 0.28 & & 0.00 \\
\hline & & & & & & & & 4.78 & & 3.69 \\
\hline Months a year village inaccessible & & & & & & & & -34.24 & & -0.12 \\
\hline & & & & & & & & 10.44 & & 2.94 \\
\hline Community adult-literacy programme & & & & & & & 0.48 & 24.93 & -0.13 & 0.37 \\
\hline & & & & & & & 0.08 & 7.01 & 0.16 & 4.50 \\
\hline $\mathrm{N}$ & & & & & & & & & & \\
\hline
\end{tabular}

The first three dependent variables were analysed using Logit regressions with fixed effects and with random effects, the latter two using OLS regressions with fixed effects and Hausman-Taylor regressions. The number next to each variable represents the coefficient, the number below the corresponding Z-score/T-statistic. Numbers in bold are significant at least at the 10 per cent level. The un-displayed control variables were not consistently significant. 